\title{
Effects of long-term strontium ranelate treatment on vertebral fracture risk in postmenopausal women with osteoporosis
}

\author{
P. J. Meunier • C. Roux • S. Ortolani • M. Diaz-Curiel • \\ J. Compston • P. Marquis • C. Cormier • G. Isaia • \\ J. Badurski • J. D. Wark • J. Collette • J. Y. Reginster
}

Received: 18 July 2008 / Accepted: 4 December 2008 /Published online: 20 January 2009

(C) The Author(s) 2009. This article is published with open access at Springerlink.com

\begin{abstract}
Summary Vertebral fractures are a major adverse consequence of osteoporosis. In a large placebo-controlled trial in postmenopausal women with osteoporosis, strontium ranelate reduced vertebral fracture risk by $33 \%$ over 4 years,
\end{abstract}

confirming the role of strontium ranelate as an effective long-term treatment in osteoporosis.

Introduction Osteoporotic vertebral fractures are associated with increased mortality, morbidity, and loss of quality-oflife (QoL). Strontium ranelate (2 $\mathrm{g} /$ day) was shown to
P. J. Meunier

Faculty Laennec, Claude Bernard University,

Rue G Paradin,

69437 Lyon Cedex 03, France

P. J. Meunier $(\bowtie)$

4 rue des Pierres Plantées,

69001 Lyon, France

e-mail: pierre.meunier@sante.univ-lyon1.fr

C. Roux

Service de Rhumatologie B, Université Paris Descartes,

Hôpital Cochin,

27 rue du Faubourg St Jacques,

75014 Paris, France

S. Ortolani

Divisione di Endocrinologia, Istituto Auxologico Italiano,

Via Ariosto, 13,

20145 Milan, Italy

M. Diaz-Curiel

Servicio de Medicina Interna, Fundación Jiménez Diaz, Avenida de los Reyes Catolicos,

28040 Madrid, Spain

J. Compston

Department of Medicine, University of Cambridge,

Addenbrooke's Hospital,

Cambridge CB1 2QQ, England

P. Marquis

MAPI Values,

15 Court Square, Suite 620,

Boston, MA 02108, USA

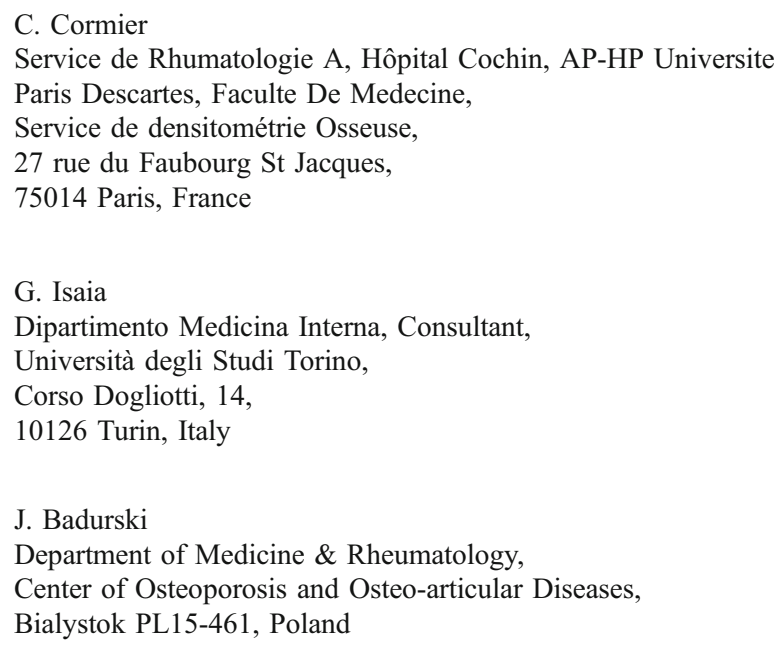

J. Badurski

Department of Medicine \& Rheumatology,

Center of Osteoporosis and Osteo-articular Diseases,

Bialystok PL15-461, Poland

\section{J. D. Wark}

Department of Medicine, Royal Melbourne Hospital,

Clinical Science Building,

3050 Parkville, VIC, Australia

J. Collette

Service de Chimie Médicale,

Centre Hospitalier Universitaire de Liège,

Hôpital du Sart Tilman, 4000 Liège 1, Belgium

\section{J. Y. Reginster}

Unité Exploration du Métabolisme Osseux, CHU Brull,

45 quai Godefroid Kurth,

4020 Liège, Belgium 
prevent bone loss, increase bone strength, and reduce vertebral and peripheral fractures. The preplanned aim of this study was to evaluate long-term efficacy and safety of strontium ranelate.

Methods A total of 1,649 postmenopausal osteoporotic women were randomized to strontium ranelate or placebo for 4 years, followed by a 1 -year treatment-switch period for half of the patients. Primary efficacy criterion was incidence of patients with new vertebral fractures over 4 years. Lumbar bone mineral density (BMD) and QoL were also evaluated.

Results Over 4 years, risk of vertebral fracture was reduced by $33 \%$ with strontium ranelate (risk reduction $=0.67, p<$ 0.001 ). Among patients with two or more prevalent vertebral fractures, risk reduction was 36\% $(p<0.001)$. QoL, assessed by the QUALIOST $^{\circledR}$, was significantly better $(p=0.025)$, and patients without back pain were greater $(p=0.005)$ with strontium ranelate than placebo over 4 years. Lumbar BMD increased over 5 years in patients who continued with strontium ranelate, while it decreased in patients who switched to placebo. Emergent adverse events were similar between groups.

Conclusion In this 4- and 5-year study, strontium ranelate is an effective and safe treatment for long-term treatment of osteoporosis in postmenopausal women.

Keywords Bone densitometry · Menopause - Osteoporotic fracture $\cdot$ Osteoporosis treatment $\cdot$ Strontium ranelate

\section{Introduction}

Vertebral fractures are one major adverse clinical consequences of osteoporosis [1]. Most vertebral fractures are precipitated by everyday activities rather than falls [2], and occurrence of a vertebral fracture is a powerful risk factor for future fractures [3]. Vertebral fractures are associated with increased mortality, long-term morbidity [4], and considerable health care costs [5] that are predicted to increase markedly over the period to 2020 [6].

Vertebral fractures, even those not recognized clinically, are also associated with substantial back pain and functional limitation [7, 8] and significant loss of quality-of-life (QoL). Both mental and physical domains of quality of life may be affected, and impairment is directly related to both severity and number of fractures $[9,10]$.

Strontium ranelate is an oral anti-osteoporotic drug that has been shown to prevent bone loss and increase bone strength in experimental studies [11]. Strontium ranelate increased bone formation in vitro, enhancing pre-osteoblastic cell replication and osteoblastic differentiation and decreasing abilities of osteoblasts to induce osteoclastogenesis via the calcium-sensing receptor $(\mathrm{CaR})$ and an increase in the OPG/RANKL ratio [12]. In postmenopausal women with osteoporosis, strontium ranelate $2 \mathrm{~g}$ /day increased bone mineral density (BMD) in a placebocontrolled, 2-year dose-response study in 353 patients [13]. The Spinal Osteoporosis Therapeutic Intervention (SOTI) trial was designed to evaluate efficacy of strontium ranelate $(2 \mathrm{~g} /$ day $)$ in reducing vertebral fractures. Over the first year and first 3 years of treatment, strontium ranelate treatment was associated with reductions of $49 \%(p<0.001)$ and $41 \%(p<0.001)$, respectively, relative to placebo, in the risk of vertebral fractures [14].

Strontium ranelate has also shown significant efficacy against peripheral fractures and hip fractures in patient at risk over 3 years [15] and 5 years [16]. The purpose of the present article is to present results from the SOTI trial relating to vertebral fracture risk, changes in BMD and QoL for the 4-year initial treatment period, and also BMD results from the fifth-year treatment-switch period.

\section{Methods}

Patients

Post-menopausal ( $\geq 5$ years) women were ambulatory Caucasian, $\geq 50$ years of age with at least one prevalent osteoporotic vertebral fracture. Mean lumbar BMD had to be $\leq 0.840 \mathrm{~g} / \mathrm{cm}^{2}$ [17]. Exclusion criteria were described elsewhere [18] and were mainly concomitant pathologies or treatment potentially interfering with bone metabolism.

\section{Study design}

Methodological details have been described previously [18]. In brief, this was an international, randomized, double-blind, placebo-controlled trial. Previous to and during the study, patients were supplemented in vitamin D and calcium according to their need [18].

Patients were randomized $(1: 1)$ to receive strontium ranelate $2 \mathrm{~g}$ /day or placebo orally for 4 years, followed by a 1 -year period in which patients in the strontium ranelate group were randomized either to switch to placebo $(50 \%$, $\mathrm{SR} /$ placebo group) or to continue on strontium ranelate $2 \mathrm{~g} /$ day $(50 \%$, SR/SR group), while all patients in the placebo group were switched to strontium ranelate $2 \mathrm{~g}$ /day (placebo/ SR group; Fig. 1).

\section{Outcome measures}

For the 4-year treatment period, the pre-planned primary efficacy criterion was the incidence of patients experiencing a new vertebral fracture. Secondary criteria included new clinical vertebral fractures, osteoporotic peripheral fractures, 
Fig. 1 Flow of patients through the study

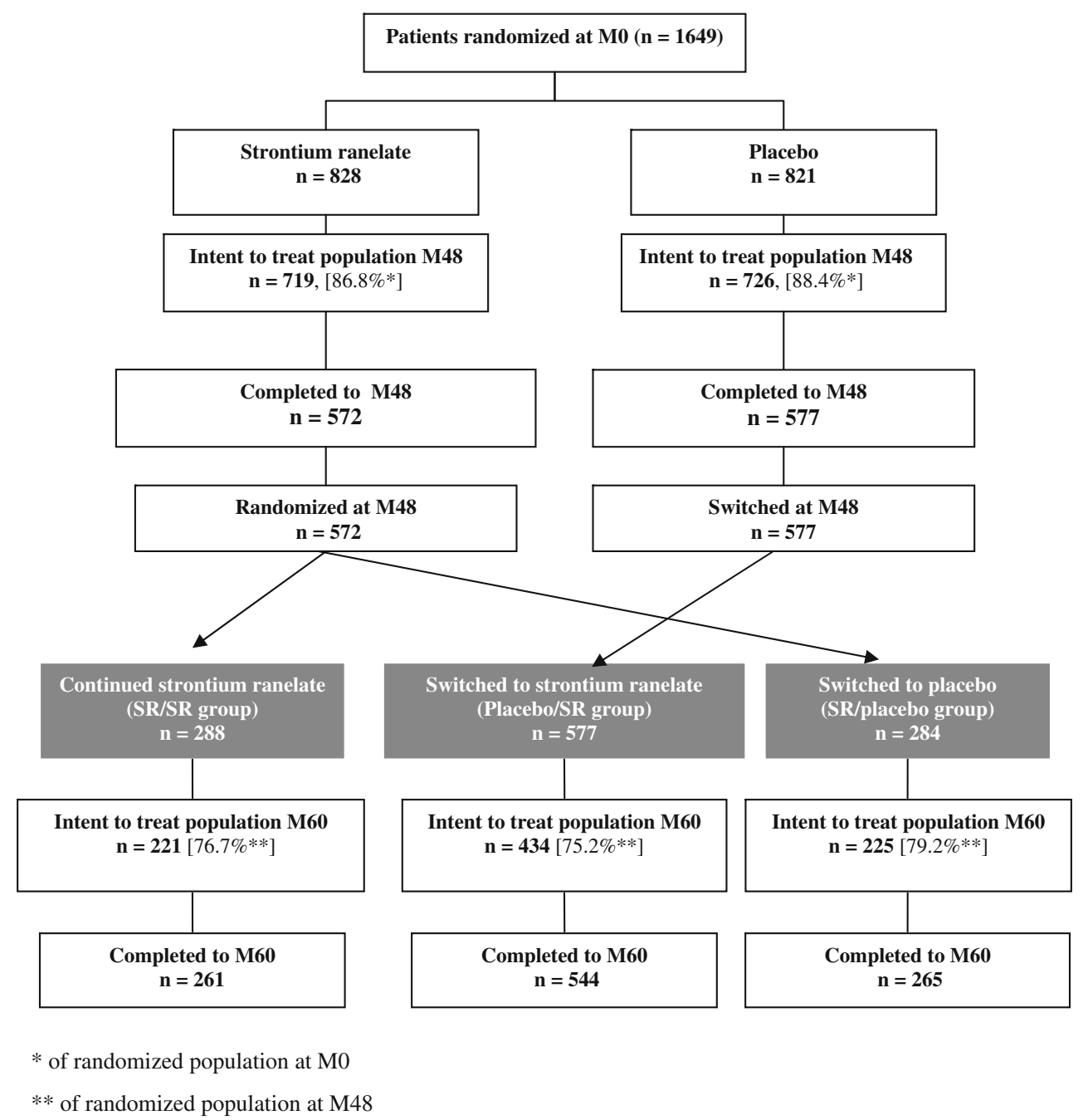

changes in body height, ${ }_{\mathrm{L} 2-\mathrm{L} 4} \mathrm{BMD}$, total hip and femoral neck BMD, bone turnover markers, and quality-of-life.

For the fifth-year treatment-switch period, the primary

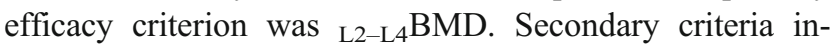
cluded total hip and femoral neck BMD, new vertebral fractures, and bone turnover markers.

Vertebral fractures were determined from radiographs taken at baseline (M0) and annually thereafter. Radiographs were analyzed semi-quantitatively [19], with a new vertebral fracture defined as a change from grade 0 to grade 1 or higher [19]. Clinical vertebral fractures were defined as new or worsening fractures with back pain and/or body height loss of $\geq 1 \mathrm{~cm}$. Radiographs were assessed centrally (CEMO, France; Pr C. Roux).

Peripheral osteoporotic fractures were determined by investigators from radiographs or hospital reports [20]. Standing body height was standardized and measured by Harpenden stadiometer at all visits.

Total hip, femoral neck, and lumbar BMD were measured by dual-energy X-ray absorptiometry (DXA) using Hologic devices at baseline and every 6 months post-baseline. A cross-calibration program was performed throughout the study [21], and all scans were analyzed centrally. Strontium distributes in bone and absorbs X-rays to a greater extent than calcium. The presence of strontium may account for approximately $50 \%$ of BMD increases measured by DXA with strontium ranelate treatment [22].

Bone turnover markers were assessed at baseline, after 3 and 6 months of treatment, and then annually during 4 years; during the fifth year, they were assessed only in patients treated for 4 years with strontium ranelate and after 51 and 60 months of treatment. Bone alkaline phosphatase (bALP) was assayed by immunoradiometric assay (Tandem $^{\circledR}-R$ Ostase ${ }^{\circledR}$, Beckman Coulter, formerly Hybritech, San Diego, CA, USA), and serum C-telopeptide cross-link of type I collagen (sCTX) was assayed using an enzymelinked immunosorbent assay (serum CrossLaps ${ }^{\circledR}$ ELISANordic Bioscience Diagnostic, formerly Osteometer BioTech, Herlev, Denmark).

Parathyroid hormone was assessed with an immunoradiometric assay (N-tact ${ }^{\circledR P T H}$ SP IRMA, Diasorin, USA). 
QoL was assessed using self-administered questionnaires: the Short-Form $36\left(\right.$ SF-36 $\left.{ }^{\circledR}\right)$, a widely used generic 36-item instrument [23], and QUALIOST ${ }^{\circledR}$, a diseasespecific 23-item instrument designed to complement the SF-36 ${ }^{\circledR}$ in postmenopausal patients with vertebral osteoporosis [24]. Both questionnaires were completed every 6 months throughout the trial. In the SF-36 ${ }^{\circledR}$, items are grouped into eight dimensions, which were further combined into summary scores for mental and physical components. In each case, scores range from 0 to 100 , with higher scores indicating better QoL. QUALIOST ${ }^{\circledR}$ contains two dimensions, physical (10 items) and emotional (13 items). Scores again range from 0 to 100 , higher scores indicate greater impairment of QoL. One QUALIOST ${ }^{\circledR}$ item (physical dimension item 6) relates specifically to back pain. The QUALIOST ${ }^{\circledR}$ cross-cultural validity and responsiveness have been validated using earlier (3-year) data from the present (SOTI) trial [25].

\section{Statistical analysis}

Randomized assignment of treatment was stratified by country and performed using permutation blocks with a fixed size of four.

All these pre-planned efficacy analyses were performed in accordance with the intention-to-treat (ITT) principle. For the M0-M48 period, ITT population for fracture incidence analysis was defined as all randomized patients who took at least one sachet of study drug and with (at least two) X-ray assessments between M0 and M48. For the M48-M60 period, ITT population was defined as all patients who performed the M48 visit, took at least one sachet of study drug between M0 and M48 and after M48, with validated ${ }_{\mathrm{L} 2-}$ ${ }_{\mathrm{L} 4} \mathrm{DXA}$ measurements at $\mathrm{M} 0$ and M48, and post M48. The ITT population for QoL analysis comprised patients from the ITT population who had at least one assessable SF-36 ${ }^{\circledR}$ (i.e., $<50 \%$ missing data) and one assessable QUALIOST ${ }^{\circledR}$ completed at baseline, plus at least one assessable SF36 ${ }^{\circledR}$ and one assessable QUALIOST ${ }^{\circledR}$ completed post baseline ( $>12$ months, until 4 years of treatment).

For the 4-year analysis, the incidence over time of patients with at least one new osteoporotic vertebral fracture and new clinical vertebral fracture were analyzed by Kaplan-Meier method. Analysis of osteoporosis-related vertebral fractures was therefore carried out on all available data (under treatment or not) up to the cutoff date of the new vertebral fracture, whatever the date of the last study visit for the patients considered. Consequently, as the population selection bias phenomenon increases year after year, any isolated yearly statistical comparison regarding fracture occurrence would provide biased (as well as inaccurate) estimates and would lead to misleading clinical interpretation. Therefore, treatment groups were compared using the Cox model over 4 years.
The incidence of vertebral fractures was adjusted for age, country, prevalent vertebral fractures, and ${ }_{\mathrm{L} 2-\mathrm{L} 4} \mathrm{BMD}$ and incidence of non-vertebral fractures was adjusted for age, country, body mass index, and femoral neck BMD. A logrank non-parametric test was used to confirm results of the Cox model. Between-group comparisons of BMD and bone markers were performed using covariance analysis with baseline value as covariate and two-tailed Student's $t$ tests. Between-group comparison of body height was performed on the change from baseline using a covariance analysis adjusted on height at baseline and prevalent vertebral fracture. The number of patients in each group with a body height loss of $\geq 1 \mathrm{~cm}$ was compared using the chi-squared test.

For the fifth-year treatment-switch period (M48 to M60), annual incidence of new vertebral fracture was estimated using a within-group 95\% confidence interval of the estimates with Kaplan-Meier method. Within-group comparisons of BMD were performed using the Student's $t$ test for paired samples and between-group comparisons using the same test for independent samples. Bone markers were analyzed using descriptive statistics. At entry in the fifth year, a between-group comparison on BMD (lumbar and femoral neck level) and on corresponding $T$ scores was performed using a two-sided Student's $t$ test for independent samples.

Between-group comparisons of the SF-36 ${ }^{\circledR}$ and QUALIOST $^{\circledR}$ total and component scores at each time point were performed using a repeated-measures analysis (mixed model), followed, in the case of non-significant treatment $\times$ time interaction, by Fisher's test. Analysis was first performed on raw data and confirmed by repeating with imputation of missing data. Missing data were replaced, taking into account fracture status of each patient. For example, for patients who had experienced a fracture and for whom the questionnaire was missing after they had their fracture, the average change in score seen in patients after they experienced a fracture was added to the last available score for that patient. Missing items within questionnaires had already been taken into account when calculating scores, with dimension scores being calculated as the mean of non-missing items only if at least half of the items in that dimension had been answered. An analysis of covariance (ANCOVA), with baseline score as covariate, was performed to compare between groups the changes between baseline and last value and between baseline and last value on treatment. The number of patients free from back pain (QUALIOST ${ }^{\circledR}$ item 6) in each group was compared using Poisson regression.

The type I error rate was set at $5 \%$ throughout.

Statistical analyses were performed by Servier, and the study was organized under the control of independent advisory and steering committees. 
Safety evaluation

Adverse events reported spontaneously by patients or elicited during interview were recorded at each study visit. Blood and urinary calcium and blood phosphorus were assessed at each visit. Hematology and biochemistry tests were performed at M0, M6, M12, and then annually. Adverse events were reviewed by a safety committee, independent from the sponsor and from the other study committees.

\section{Results}

Patients

A total of 1,649 patients were randomized: 828 to strontium ranelate and 821 to placebo. Of these, 1,149 patients $(69.7 \%)$ completed the 4-year treatment period (strontium ranelate, 572 patients; placebo, 577 patients) and entered the fifth-year treatment-switch period. All placebo-treated patients were switched to strontium ranelate, and strontium ranelate-treated patients were randomized either to continue with strontium ranelate (SR/SR group, $n=288$ ) or to switch to placebo (SR/placebo group, $n=284$; Fig. 1). The proportion of randomized patients included in the ITT population at M48 was $87.6 \%$. At M60, 1,070 patients completed the study; however, 880 patients, representing $76.6 \%$ of those who entered the fifth year, were included in the ITT population at M60. The reasons for exclusion of these 190 patients were absence of treatment from M48 and absence of assessable lumbar BMD at baseline, M48, or after M48.
Demographic and clinical characteristics of randomized patients are shown in Table 1. There were no relevant between-group differences. At entry to the fifth-year treatment-switch period, BMD values and corresponding $T$-scores were lower in patients on placebo during the 4year treatment period. In addition, a slight between-group difference was observed for patients having taken concomitant treatment for osteoporosis during the study $(4.2 \%$ and $2.1 \%$ patients in the $\mathrm{SR} / \mathrm{SR}$ and $\mathrm{SR} /$ placebo groups versus $6.4 \%$ in the placebo/SR group). No other relevant betweengroup differences were observed for the remaining baseline characteristics.

\section{Efficacy}

\section{Vertebral fractures and $B M D$}

Four-year treatment period The risk of new vertebral fracture over the M0 to M48 period was reduced by $33 \%$ with strontium ranelate, relative to placebo [risk reduction (RR), $0.67 ; 95 \% \mathrm{CI}(0.55,0.81), p<0.001]$. The number of patients needed to treat for 4 years to prevent one new vertebral fracture was 11 [95\% CI $(7,24)]$. Among severely affected patients (with two or more prevalent vertebral fractures at baseline), risk reduction with strontium ranelate was $36 \%$ (RR, $0.64 ; 95 \%$ CI $(0.50,0.81), p<0.001]$. The total number of new vertebral fractures was significantly lower in the strontium ranelate group (275) than in the placebo group $(421 ; p<0.001)$. The risk of new clinical vertebral fracture was reduced by $36 \%$ with strontium ranelate relative to placebo $[\mathrm{RR}, 0.64 ; 95 \% \mathrm{CI}(0.49,0.83)$, $p<0.001$ ] (Fig. 2).

Table 1 Baseline characteristics at year 0 and at year 4 of the M48 and M60 ITT populations, expressed as mean \pm standard deviation unless otherwise stated

\begin{tabular}{|c|c|c|c|c|c|}
\hline & \multicolumn{2}{|l|}{ Year 0} & \multicolumn{3}{|l|}{ Year 4} \\
\hline & $\begin{array}{l}\text { Strontium } \\
\text { ranelate, } N=719\end{array}$ & $\begin{array}{l}\text { Placebo, } \\
N=726\end{array}$ & $\begin{array}{l}\mathrm{SR} / \mathrm{SR}, \\
N=221\end{array}$ & $\begin{array}{l}\text { SR/placebo, } \\
N=225\end{array}$ & $\begin{array}{l}\text { Placebo/SR, } \\
N=434\end{array}$ \\
\hline Age, years & $69.4 \pm 7.2$ & $69.3 \pm 7.3$ & $72.1 \pm 6.9$ & $72.1 \pm 6.7$ & $72.1 \pm 6.9$ \\
\hline Time since menopause (years) & $22.1 \pm 8.8$ & $21.7 \pm 8.8$ & $24.5 \pm 8.5$ & $25.0 \pm 8.7$ & $24.3 \pm 8.3$ \\
\hline $\begin{array}{l}\text { One or more prevalent vertebral } \\
\text { fracture, } n \text { patients }(\%)\end{array}$ & $628(87.5)$ & $626(86.3)$ & $192(86.9)$ & $197(87.6)$ & $372(86.1)$ \\
\hline $\begin{array}{l}\text { Number of prevalent vertebral } \\
\text { fractures }\end{array}$ & $2.5 \pm 2.0$ & $2.5 \pm 2.1$ & $2.7 \pm 2.2$ & $2.8 \pm 2.1$ & $3.1 \pm 2.7$ \\
\hline Lumbar BMD $\left(\mathrm{g} / \mathrm{cm}^{2}\right)$ & $0.731 \pm 0.125$ & $0.720 \pm 0.118$ & $0.849 \pm 0.158^{*}$ & $0.862 \pm 0.163^{*}$ & $0.717 \pm 0.127$ \\
\hline Lumbar $T$-score & $-3.52 \pm 1.30$ & $-3.64 \pm 1.23$ & & & \\
\hline Femoral neck BMD $\left(\mathrm{g} / \mathrm{cm}^{2}\right)$ & $0.591 \pm 0.086$ & $0.590 \pm 0.093$ & $0.655 \pm 0.888^{*}$ & $0.643 \pm 0.087 *$ & $0.581 \pm 0.094$ \\
\hline Femoral neck $T$-score & $-2.78 \pm 0.77$ & $-2.79 \pm 0.84$ & & & \\
\hline bALP (ng/mL) & $12.3 \pm 4.5$ & $12.8 \pm 4.9$ & & & \\
\hline sCTX (ng/mL) & $0.51 \pm 0.24$ & $0.52 \pm 0.24$ & & & \\
\hline
\end{tabular}

${ }^{*} p<0.001$ for the difference SR/SR-placebo/SR or SR/placebo-placebo/SR (two sided Student's $t$ test for independent samples) 


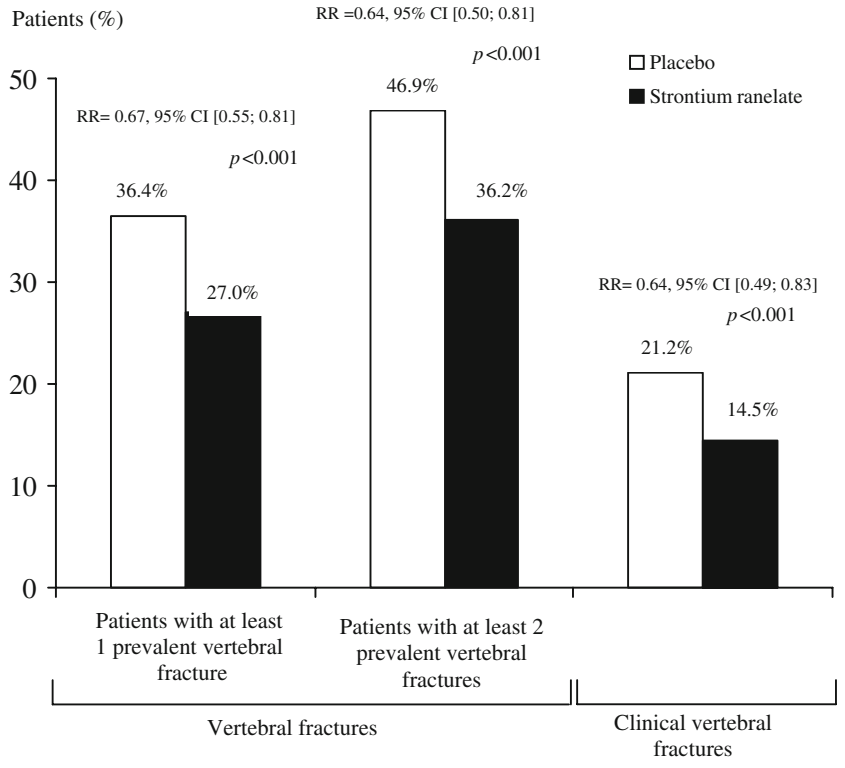

Fig. 2 The proportion of patients who experienced new vertebral fracture(s) during the M0-M48 period

The risk of peripheral fracture was not significantly different over 4 years between the two groups $[R R=0.92$, $95 \%$ CI $(0.72,1.19)]$.

Mean reduction in body height was less in the strontium ranelate group compared with placebo [estimated betweengroup difference (SE) (mm), $2.1(0.8), p=0.007]$, and the proportion of patients with a reduction in body height of $\geq 1 \mathrm{~cm}$ was significantly lower in the strontium ranelate group (36.6\%) than with placebo $(42.1 \% ; p=0.034)$.

BMD increased over time at all sites measured in the strontium ranelate group but decreased slightly in the placebo group. The between-group differences for the change from baseline in BMD at the different sites were $14.6 \%$ for the lumbar site, $8.7 \%$ for the femoral neck, and $9.8 \%$ for the total hip site $(p<0.001$ for each site).

Serum concentration of bALP was higher in the strontium ranelate group than in the placebo group from M3 to M48, with significant between-group difference on the change from baseline to end (change from baseline to end, $2.5 \pm 4.5$ and $1.9 \pm 5.8 \mathrm{ng} / \mathrm{mL}$ in the strontium ranelate and placebo groups, respectively; $p=0.031$ ). Concentration of sCTX was lower in the strontium ranelate group than in the placebo group from M3 to M48, with a significant between-group difference on the change from baseline to end (change from baseline to end, $0.01 \pm 0.30$ and $0.06 \pm 0.27 \mathrm{ng} / \mathrm{mL}$ in the strontium ranelate and placebo groups, respectively; $p<0.001$ ).

Fifth-year treatment period In the SR/SR group, the progressive increase in ${ }_{\mathrm{L} 2-\mathrm{L} 4} \mathrm{BMD}$ seen throughout the 4 years of the trial continued during the fifth year, with a further increase of $1.2 \pm 5.8 \%$ between M48 and end on treatment (Fig. 3). In the SR/placebo group, the increase in BMD began to reverse after the switch to placebo $(-3.2 \pm$ $5.8 \%$ ) between M48 and end on treatment, although BMD was still substantially higher at M60 $\left(0.819 \pm 0.147 \mathrm{~g} / \mathrm{cm}^{2}\right)$ compared with M0 $\left(0.734 \pm 0.123 \mathrm{~g} / \mathrm{cm}^{2}\right)$. Both the increase in ${ }_{\text {L2-L4 }} \mathrm{BMD}$ in the SR/SR group and the decrease in the SR/placebo group between M48 and end on treatment were significant $(p<0.001$ and $p=0.002$, respectively). BMD in the placebo/SR group increased after switch to strontium ranelate; the increase between M48 and end on treatment $(5.3 \pm 7.3 \%)$ was similar to the increase seen in strontium ranelate-treated patients during the first year (M0-M12) of the trial $(6.4 \pm 7.7 \%)$.

BMD changes at other measured sites were similar to those at the L2-L4 site. Significant differences were seen in the change in BMD between M48 and end over 5 years between the SR/SR group and the SR/placebo group at each site $(p<0.001$ in each case; Table 2$)$.

The decrease in BMD in the SR/placebo group was not associated with a significant between-group difference in the incidence of new vertebral fractures over the fifth year of treatment: $6.9 \%$ (14 patients) in the SR/SR group compared with $8.9 \%$ (19 patients) in the SR/placebo group $(p=0.463)$. However, these results should be interpreted with caution since the number of patients with a fracture is small.

Bone markers (fifth year) After discontinuation of treatment, a significant decrease in bALP from M48 to last observation on treatment (from 15.2 \pm 5.2 to $11.6 \pm 3.6 \mathrm{ng} /$ $\mathrm{mL}, p<0.001$ ) and an increase in $\mathrm{sCTX}$ (from $0.552 \pm 0.263$ to $0.588 \pm 0.225 \mathrm{ng} / \mathrm{mL}, p=0.038$ ) were observed.

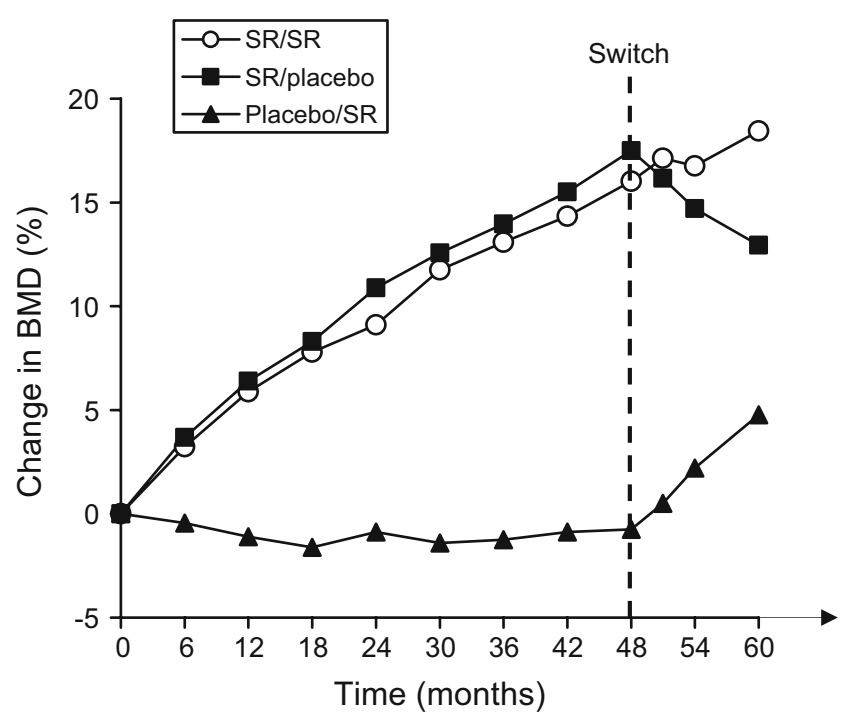

Fig. 3 Changes in bone mineral density (BMD) at the lumbar L2-L4 site with time throughout the trial. Treatment switch at 48 months is indicated by vertical dashed line 
Table 2 Relative changes (\%) in bone mineral density between M48 and last observation on treatment in patients continuing on strontium ranelate (SR/SR group) and switching to placebo (SR/placebo group)

\begin{tabular}{|c|c|c|c|c|c|}
\hline & $\begin{array}{l}\text { SR/SR group } \\
(\text { mean } \pm \text { SD), } N=221\end{array}$ & $\begin{array}{l}\text { SR/placebo group } \\
(\text { mean } \pm \text { SD), } N=225\end{array}$ & $\begin{array}{l}\text { Between-group } \\
\text { difference }(\mathrm{SE})^{\mathrm{a}}\end{array}$ & $95 \% \mathrm{CI}$ & $p$ value \\
\hline Lumbar L2-L4 & $1.21 \pm 5.78(n=207)$ & $-3.22 \pm 5.79(n=212)$ & $4.43(0.57)$ & $3.32 ; 5.54$ & $<0.001$ \\
\hline Femoral neck & $0.11 \pm 4.16(n=199)$ & $-2.12 \pm 5.79(n=207)$ & $2.22(0.50)$ & $1.24 ; 3.21$ & $<0.001$ \\
\hline Total hip & $0.41 \pm 3.02(n=199)$ & $-2.53 \pm 4.36(n=207)$ & $2.94(0.37)$ & $2.21 ; 3.67$ & $<0.001$ \\
\hline
\end{tabular}

${ }^{a} \mathrm{SR} / \mathrm{SR}$ group minus $\mathrm{SR} /$ placebo group

Quality of life (fourth year) A total of 1,250 patients $(87 \%$ of the ITT population) were assessed for QoL (strontium ranelate $n=623$, placebo $n=627$ ). For the SF-36 ${ }^{\circledR}$ questionnaire, there were no significant differences between the treatment groups for the mental and physical component summary scores. Among the individual SF-36 ${ }^{\circledR}$ dimensions, a significant between-group difference on the change from baseline to last value and on the change from baseline to last value on treatment was observed for the General Health Perception dimension ( $p=0.043$ and $p=0.012$, respectively).

QUALIOST ${ }^{\circledR}$ global scores were lower (indicating better QoL) in the strontium ranelate group than in the placebo group at each post-baseline assessment and significant between-group differences in favor of strontium ranelate in the change from baseline to endpoint (mean change from baseline in the strontium ranelate group= -0.06 and mean change from baseline in the placebo group $=1.92, p=0.020$ ) and from baseline to endpoint on treatment (mean change from baseline in the strontium ranelate group $=-0.40$ and mean change from baseline in the placebo group $=1.63, p=0.015)$ were observed.

When the physical and emotional QUALIOST ${ }^{\circledR}$ dimensions were considered separately, a statistically significant between-group difference of the change from baseline to last value and from baseline to last value in treatment in favor of strontium ranelate was observed for both emotional score ( $p=0.025$ and $p=0.012$, respectively) and physical score ( $p=0.022$ and $p=0.034$, respectively; Fig. 4).

Proportion of patients free of back pain (patients who answered 'not at all' to 'Have you had pain in the middle or upper part of your back?', QUALIOST ${ }^{\circledR}$ item 6) after 4 years of treatment was $28 \%$ higher in the strontium ranelate group than with placebo $(p=0.005)$. Indeed, $14.6 \%$ of patients receiving strontium ranelate versus $11.2 \%$ of patients receiving placebo were free of back pain [RR, 1.28; $95 \%$ CI $(1.08,1.52)]$.

\section{Safety}

In all, over 4 years, 739 patients in the strontium ranelate group (89.5\%) and 720 patients in the placebo group $(88.5 \%)$ reported at least one emergent adverse event under treatment. Diarrhea $(6.3 \%$ versus $3.8 \%$, respectively) and nausea $(5.2 \%$ versus $3.8 \%$, respectively) were more frequently reported in the strontium ranelate group than in the placebo group. Skin disorders were reported similarly in both groups $(14.5 \%$ in the strontium ranelate group and $15.1 \%$ in the placebo group), including dermatitis and eczema $(2.1 \%$ versus $1.8 \%$ and $1.0 \%$ versus $1.2 \%$, respectively). Over 4 years, four serious adverse events in each group concerning skin disorders were reported (one dermatitis and one contusion in each group, a pemphigoid and a lichen planus in the strontium ranelate group, and two skin ulcers in the placebo group). None were considered as related to the study drug by the investigators.

Over 4 years, the number of patients reporting an embolism or a venous thrombosis was eight and five in the strontium ranelate and placebo groups, respectively.

In the fifth year, in patients starting strontium ranelate (placebo/SR group), the number of emergent adverse events reported was similar to the SR/SR and SR/placebo groups (55.7\% versus $56.7 \%$ and $55.5 \%$, respectively). Diarrhea, nausea, and headache were more frequently reported. These events occurred mainly during the first 3 months of

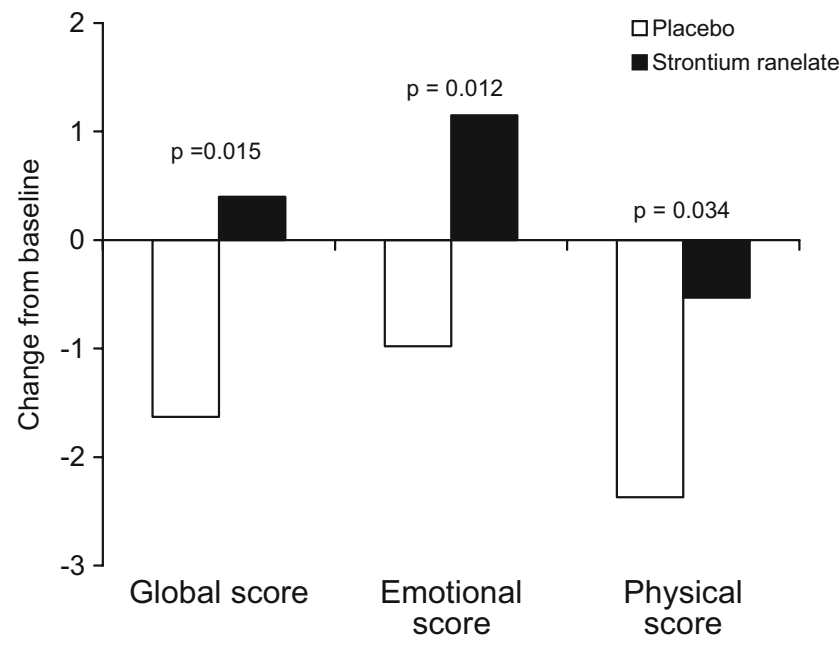

Fig. 4 Changes from baseline to last evaluation (baseline-endpoint) during the M0-M48 treatment period in quality of life assessed by QUALIOST $^{\circledR}$ global score, emotional score, and physical score in the ITT population on treatment (ANCOVA). $p$ value difference versus the placebo group 
treatment. Skin and subcutaneous disorders were reported similarly in the three groups $(5.5 \%$ in the SR/SR group, $7.3 \%$ in the SR/placebo group, and $4.3 \%$ in the placebo/SR group). Two serious adverse events classified as skin disorder occurred: one contusion due to a fall in the placebo/SR group and one in the SR/placebo. None was considered as related to the study drug.

Serum creatinine kinase concentrations increased in some patients starting strontium ranelate. High levels (concentration greater than three times the upper value of the normal reference range) were detected in $0.7 \%$ of the patients (three patients), but none reached five times the upper value of the normal reference range.

Concerning calcium homeostasis, over 4 years, mild decreases in calcium and parathyroid hormone $(\mathrm{PTH})$ serum levels were observed in the strontium ranelate group (from $2.38 \pm 0.13 \mathrm{mmol} / \mathrm{L}$ at baseline to $2.22 \pm 0.10 \mathrm{mmol} / \mathrm{L}$ at end and from $30.98 \pm 12.71 \mathrm{pg} / \mathrm{mL}$ at baseline to $28.75 \pm$ $11.60 \mathrm{pg} / \mathrm{mL}$ at end, respectively), while blood phosphorus concentration slightly increased (from $1.22 \pm 0.19 \mathrm{mmol} / \mathrm{L}$ at baseline to $1.31 \pm 0.17 \mathrm{mmol} / \mathrm{L}$ at end). These changes were of too small magnitude to have clinical relevance. During the fifth year, in the group which stopped strontium ranelate, trends to inverse changes were observed; slight increase in serum calcium concentration (from $2.31 \pm 0.93$ to $2.36 \pm 0.09 \mathrm{mmol} / \mathrm{L}$ ) and decrease in blood phosphorus concentration $(1.31 \pm 0.16$ to $1.22 \pm 0.14 \mathrm{mmol} / \mathrm{L})$.

\section{Discussion}

The main result of this pre-planned analysis is that long-term treatment (4 years) with strontium ranelate produced a significant $33 \%$ reduction in the risk of vertebral fractures. A similar reduction (36\%) was seen in the subset of severely affected patients with $\geq 2$ prevalent vertebral fractures at baseline. The reductions in fracture risk were associated with a progressive increase in BMD of the lumbar and hip regions that extended throughout the treatment period.

Few studies of anti-osteoporotic drugs using randomized initial treatment periods of duration comparable to the present trial (4 years) and in the same type of patients are published. In patients without prevalent vertebral fracture, alendronate $(10 \mathrm{mg} /$ day $)$ reduced by $44 \%$ vertebral fractures over 4 years, but no data were available in patients with prevalent vertebral fracture [26]. Raloxifene reduced vertebral fracture by $34 \%$ over 4 years in patients with prevalent vertebral fracture [27]. The 33\% risk reduction seen over 4 years in this study is of similar magnitude to these results. No data are available for risedronate for initial randomized periods of 4 years or longer, but a reduction in vertebral fractures of $59 \%$ was reported from a smaller (265 patients) 2-year extension to a 3-year study [28].
The reduction in risk of vertebral fractures of $33 \%$ over 4 years in the present study is smaller than that seen in the corresponding analysis over 3 years (41\%) [14]. An apparent decrease in the size of risk reduction achieved with greater treatment duration has been reported in previous studies of other anti-osteoporotic drugs. For risedronate, risk reductions of $65 \%$ and $61 \%$ seen at 1 year decreased to $41 \%$ and $49 \%$, respectively, over 3 years [29, 30]. Comparisons of cumulative endpoints at different times during a long-term study must therefore be interpreted with caution. The patients at risk of a given endpoint, although well balanced between treatment groups in terms of disease characteristics and level of risk at randomization, become progressively unbalanced (for example, due to censoring of fracture cases, attrition of more severely affected patients, and introduction of concomitant osteoporosis medication) over time if treatments differ in efficacy. Attrition of high-risk patients will be more rapid in the low efficacy (generally placebo) group.

In the later parts of the study, therefore, the placebo group will effectively contain fewer high-risk patients than the active treatment group, and the effects of active treatment will appear to be reduced.

The vertebral antifracture efficacy of strontium ranelate over 4 years in this study has also been confirmed over 5 years in the Treatment of Peripheral Osteoporosis study [16].

Many factors contribute to bone fragility that leads to osteoporotic fractures [31]. One important mechanism is the progressive net loss of bone due to a greater degree of bone resorption than formation at focal remodeling sites, leading to an overall deficit in bone formation in later adult life. In postmenopausal women, the rate of net bone loss is accelerated by an increase in the intensity of bone remodeling in response to reduced estrogen levels. Antiresorptive agents such as bisphosphonates and raloxifene reduce the rate of bone remodeling, reflected in decreases in markers of both bone formation and bone resorption [32, 33]. Strontium ranelate appears to have a different mode of operation. In various animal models, strontium ranelate has been shown to prevent bone loss by increasing bone formation and decreasing bone resorption [34]. These in vivo results were consistent with in vitro data where strontium ranelate has been shown to reduce bone resorption by osteoclasts and to stimulate bone formation by osteoblasts [34, 35]. It has been demonstrated in vitro that strontium ranelate is an agonist of the $\mathrm{CaR}$ and is able to stimulate the replication of osteoblasts through the activation of $\mathrm{CaR}$ [36]. $\mathrm{CaR}$ is one of the major molecular determinants involved in controlling the cations concentration through regulation of PTH [37]. The slight decrease in serum calcium and PTH in association with a slight increase in blood phosphorus observed in this study is in agreement with an action mediated through the $\mathrm{CaR}$ in postmenopausal women. 
Consistent with the dual mode of action of strontium ranelate, analysis of serum markers of bone metabolism over the first 3 and 4 years of the SOTI study showed that strontium ranelate treatment was associated with a small but significant increase in bALP and a significant decrease in SCTX, relative to placebo [12]. Following treatment withdrawal, results obtained were in agreement with this dual mode of action as they show a significant decrease in bALP and an increase in SCTX. These changes are already observed 3 months after treatment discontinuation, suggesting a relatively rapid release of strontium from bone.

In the present analysis, patients who continued on strontium ranelate in the main treatment period and in the treatment-switch period showed a progressive increase in BMD throughout the entire 5-year period. The increase in

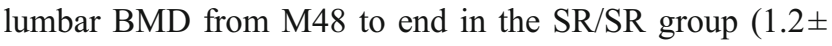
$5.8 \%)$ is clinically significantly smaller than in the placebo/ SR group (5.3 $\pm 7.3 \%)$. Increase of bone density with strontium ranelate may be due to different effects: increase in bone mass, increase in the degree of mineralization, or artifactual increase of BMD due to the presence of strontium in bone. Studies on bone biopsies have demonstrated that the degree of mineralization is not modified compared to placebo after 3 years of treatment [38]. Regarding the bone strontium content, it has been demonstrated that bone strontium content reached a plateau after 3 years of treatment [39]. This plateau might explain at least partly the smaller increase in BMD after 4 years of treatment compared to the first year of treatment and suggested that strontium ranelate continue to increase bone mass despite the plateau observed in bone strontium content. Furthermore, a strong relationship between the increase in BMD and a subsequent reduction of the risk to have a new vertebral or hip fracture have been demonstrated in strontium ranelate-treated patients indicating that BMD may be of interest to monitor those patients for 3 years [40,41]. After treatment withdrawal, patients who switched to placebo at 4 years experienced a significant reduction in BMD, showing effects of strontium ranelate to be progressively reversible and reflecting clearance of strontium from bone. Decrease observed after treatment cessation is also suggesting that BMD may be followed up after a treatment with strontium ranelate.

After 3 years, strontium ranelate treatment was associated with significant beneficial effect on QoL, relative to placebo, assessed by QUALIOST ${ }^{\circledR}$, a validated diseasetargeted QoL instrument [24, 25, 42]. These results are confirmed after 4 years of treatment: Both the emotional and physical components of the global QUALIOST ${ }^{\circledR}$ score were improved in comparison to placebo ( $p=0.012$ and $p=$ 0.034 , respectively).

Relative to baseline, placebo-treated patients showed an initial improvement in global QUALIOST ${ }^{\circledR}$ score at the 6- month assessment, followed by a progressive worsening throughout the remainder of the 4-year treatment period, with scores at the last four assessments worse than at baseline. The strontium ranelate group showed significant benefits on QoL, relative to baseline, at all assessments, indicating that strontium ranelate prevented or delayed the progressive worsening of QoL with time seen in placebo-treated osteoporotic women.

The magnitude of the difference in the change of QUALIOST ${ }^{\circledR}$ total score from baseline to last assessment between the strontium ranelate and placebo groups was clinically relevant as it reached approximately 2.0 ; this may be compared with the difference of 1.38 observed using the same instrument between patients with one new osteoporotic fracture and patients without new fracture [24]. It is important to note that these changes represent predominantly the longterm effects of fractures on QoL; soon after the occurrence of fracture, the impact on QoL may be larger.

Although the impact of osteoporotic fractures on QoL has been explored in several studies, there have been relatively few studies evaluating the effects of anti-osteoporotic drugs on QoL. One year of treatment with alendronate or calcitonin significantly reduced pain and improved QoL compared with calcium supplementation in a study of 151 patients [43]. Raloxifene treatment had no significant effect, relative to placebo, on QoL over 3 years [44]. A meta-analysis of five studies indicated that teriparatide treatment reduced the risk of new or worsening back pain, although wider QoL was not evaluated [45]. To our knowledge, the present study is the first large, long-term randomized study to demonstrate preplanned beneficial effects of an anti-osteoporotic drug on back pain and QoL.

In conclusion, in this 5-year randomized trial in postmenopausal women with osteoporosis, long-term treatment with strontium ranelate $2 \mathrm{~g}$ /day was associated with a $33 \%$ reduction in the risk of vertebral fractures, relative to placebo, over a 4-year treatment period. The reduction in fractures was accompanied by a significant improvement in QoL and increase in the number of patients free of back pain. BMD increased progressively throughout 4 and 5 years of strontium ranelate treatment, and began to decline in those patients switched from strontium ranelate to placebo at 4 years. This decrease in BMD following treatment cessation may have reflected strontium elimination from bone. Strontium ranelate represents an effective first-line intervention for long-term treatment in postmenopausal women with osteoporosis.

\section{Acknowledgments This study was sponsored by Servier.}

Conflicts of interest Dr. Colette and Mr. Marquis have no conflict of interest. Dr. Meunier, Dr. Ortolani, Dr. Roux, Dr. Wark, and Dr. Diaz Curiel have received consulting fees from Servier. Dr. Compston and Dr Reginster have received consulting fees, lecture fees and research grant from Servier. 
Open Access This article is distributed under the terms of the Creative Commons Attribution Noncommercial License which permits any noncommercial use, distribution, and reproduction in any medium, provided the original author(s) and source are credited.

\section{References}

1. European Prospective Osteoporosis Study (2002) Incidence of vertebral fracture in Europe: results from the European Prospective Osteoporosis Study (EPOS). J Bone Miner Res 17:716-724

2. Cummings SR, Melton LJ, III (2002) Epidemiology and outcomes of osteoporotic fractures. Lancet 359:1761-1767

3. Klotzbuecher CM, Ross PD, Landsman PB et al (2000) Patients with prior fractures have an increased risk of future fractures: a summary of the literature and statistical synthesis. J Bone Miner Res 15:721-739

4. Center JR, Nguyen TV, Schneider D et al (1999) Mortality after all major types of osteoporotic fracture in men and women: an observational study. Lancet 353:878-882

5. Puffer S, Torgerson DJ, Sykes D et al (2004) Health care costs of women with symptomatic vertebral fractures. Bone 35:383-386

6. Schwenkglenks M, Lippuner K, Hauselmann HJ et al (2005) A model of osteoporosis impact in Switzerland 2000-2020. Osteoporos Int 16:659-671

7. Nevitt MC, Ettinger B, Black DM et al (1998) The association of radiographically detected vertebral fractures with back pain and function: a prospective study. Ann Intern Med 128:793-800

8. Oleksik AM, Ewing S, Shen W et al (2005) Impact of incident vertebral fractures on health related quality of life (HRQOL) in postmenopausal women with prevalent vertebral fractures. Osteoporos Int 16:861-870

9. Brenneman SK, Barrett-Connor E, Sajjan S et al (2006) Impact of recent fracture on health-related quality of life in postmenopausal women. J Bone Miner Res 212:809-816

10. Fechtenbaum J, Cropet C, Kolta S et al (2005) The severity of vertebral fractures and health-related quality of life in osteoporotic postmenopausal women. Osteoporos Int 16:2175-2179

11. Marie PJ, Ammann P, Boivin G et al (2001) Mechanisms of action and therapeutic potential of strontium in bone. Calcif Tissue Int 69:121-129

12. Brennan TC, Rybchyn MS, Halbout P et al (2007) Strontium ranelate effects in human osteoblasts support its uncoupling effect on bone formation and bone resorptions. Bone Miner Res 22 (Suppl.1):S139

13. Meunier PJ, Slosman DO, Delmas PD et al (2002) Strontium ranelate: dose-dependent effects in established postmenopausal vertebral osteoporosis - a 2-year randomized placebo controlled trial. J Clin Endocrinol Metab 87:2060-2066

14. Meunier PJ, Roux C, Seeman E et al (2004) The effects of strontium ranelate on the risk of vertebral fracture in women with postmenopausal osteoporosis. New Engl J Med 350:459-468

15. Reginster JY, Seeman E, De Vernejoul MC et al (2005) Strontium ranelate reduces the risk of nonvertebral fractures in postmenopausal women with osteoporosis: Treatment of Peripheral Osteoporosis (TROPOS) study. J Clin Endocrinol Metab 90:2816-2822

16. Reginster JY, Felsenberg D, Boonen S et al (2008) Effects of long-term strontium ranelate treatment on the risk of non-vertebral and vertebral fractures in postmenopausal osteoporosis: results of a 5-year, randomized, placebo-controlled trial. Arthritis and Rheumatism 58(6):1687-1695

17. Slosman DO, Rizzoli R, Pichard C et al (1994) Longitudinal measurement of regional and whole-body bone mass in young healthy adults. Osteoporos Int 4:185-190

18. Meunier PJ, Reginster JY (2003) Design and methodology of the phase 3 trials for the clinical development of strontium ranelate in the treatment of women with postmenopausal osteoporosis. Osteoporos Int 14(Suppl 3):S66-S76

19. Genant HK, Wu CY, van Kuijk C et al (1993) Vertebral fracture assessment using a semiquantitative technique. J Bone Miner Res $8: 1137-1148$

20. Melton LJ III, Thamer M, Ray NF et al (1997) Fractures attributable to osteoporosis: report from the National Osteoporosis Foundation. J Bone Miner Res 12:16-23

21. Slosman DO, Provvedini DM, Meunier PJ et al (1999) The use of different dual $\mathrm{x}$-ray absorptiometry brands in a multicenter clinical trial. J Clin Densitom 2:37-44

22. Nielsen SP, Slosman D, Sorensen OH et al (1999) Influence of strontium on bone mineral density and bone mineral content measurements by dual X-ray absorptiometry. J Clin Densitom 2:371-379

23. Ware JE, Kosinski MK, Keller SD (1994) SF-36 physical and mental health summary scales: a users manual. The Health Institute, New England Medical Center, Boston, MA, USA

24. Marquis P, Cialdella P, De la Loge C (2001) Development and validation of a specific quality of life module in post-menopausal women with osteoporosis: the QUALIOST. Qual Life Res 10:555-566

25. De la Loge C, Sullivan K, Pinkney R et al (2005) Cross-cultural validation and analysis of responsiveness of the QUALIOST: QUAlity of Life questionnaire In OSTeoporosis. Health Qual Life Outcomes 3:69

26. Cummings SR, Black DM, Thompson DE et al (1998) Effect of alendronate on risk of fracture in women with low bone density but without vertebral fractures: results from the Fracture Intervention Trial. JAMA 280:2077-2082

27. Delmas PD, Ensrud KE, Adachi JD et al (2002) Efficacy of raloxifene on vertebral fracture risk reduction in postmenopausal women with osteoporosis: four-year results from a randomised clinical trial. J Clin Endocrinol Metab 87:3609-3617

28. Sorensen OH, Crawford GM, Mulder H et al (2003) Long-term efficacy of risedronate: a 5-year placebo-controlled clinical experience. Bone 32:120-126

29. Harris ST, Watts NB, Genant HK et al (1999) Effects of risedronate treatment on vertebral and nonvertebral fractures in women with postmenopausal osteoporosis: a randomized controlled trial. JAMA 282:1344-1352

30. Reginster J-Y, Minne HW, Sorensen OH et al (2000) Randomized trial of the effects of risedronate on vertebral fractures in women with established postmenopausal osteoporosis. Osteoporos Int 11:83-91

31. Seeman E (2002) Pathogenesis of bone fragility in women and men. Lancet 359:1841-1850

32. Stepan JJ, Alenfeld F, Boivin G et al (2003) Mechanisms of action of antiresorptive therapies of postmenopausal osteoporosis. Endocr Regul 37:225-238

33. Hansdottir H, Franzson L, Prestwood K, Sigurdsson G (2004) The effect of raloxifene on markers of bone turnover in older women living in long-term care facilities. J Am Geriatr Soc 52:779-783

34. Marie PJ (2005) Strontium ranelate: a novel mode of action of optimizing bone formation and resorption. Osteoporos Int 16 (Suppl 1):S7-S10

35. Baron R, Tsouderos Y (2002) In vitro effects of S12911-2 on osteoclast function and bone marrow macrophage differentiation. Eur J Pharmacol 450:11-17

36. Chattopadhyay N, Quinn SJ, Kifor O (2007) The calcium-sensing receptor $(\mathrm{CaR})$ is involved in strontium ranelate-induced osteoblast proliferation. Biochem Pharmacol 74:438-447

37. Brown EM, Pollak M, Hebert SC (1998) The extracellular calcium-sensing receptor: its role in health and disease. Annu Rev Med 49:15-29 
38. Boivin G, Farlay D, Simi C, Meunier PJ (2006) Bone strontium distribution and degree of mineralisation of bone in postmenopausal women treated with strontium ranelate for 2 or 3 years. Osteoporos Int 17:S86

39. Boivin G, Meunier PJ (2006) Bone strontium content reaches a plateau after 3 years of treatment with strontium ranelate $2 \mathrm{~g}$ per day. Arthritis Rheum 9(Suppl):S59040

40. Bruyere O, Roux C, Detilleux J et al (2007) Relationship between bone mineral density changes ans fracture risk reduction in patients treated with strontium ranelate. J Clin Endocrinol Metab 92(8):3076-3081

41. Bruyere O, Roux C, Badurski J et al (2007) Relationship between change in femoral neck bone mineral density and hip fracture incidence during treatment with strontium ranealte. Cur Med Res Op 23(12):3041-45
42. Marquis P, Roux C, de la Loge C et al (2007) Strontium ranelate prevents quality of life impairment in post-menopausal women with established vertebral osteoporosis. Osteoporos Int 19:503-510

43. Dursun N, Dursun E, Yalcin S (2001) Comparison of alendronate, calcitonin and calcium treatments in postmenopausal osteoporosis. Int J Clin Pract 55:505-509

44. Silverman SL, Minshall ME, Shen W et al (2001) The relationship of health-related quality of life to prevalent and incident vertebral fractures in postmenopausal women with osteoporosis: results from the Multiple Outcomes of Raloxifene Evaluation Study. Arthritis Rheum 44:2611-2619

45. Nevitt MC, Chen P, Dore RK et al (2006) Reduced risk of back pain following teriparatide treatment: a meta-analysis. Osteoporos Int 17:273-280 